\title{
Brönsted Acidic Ionic Liquid 1-(1-Propylsulfonic)-3-methylimidazolium-Chloride Catalyzed Hydrolysisof D-Cellobiose in Aqueous Medium
}

\author{
Ananda S. Amarasekara and Bernard Wiredu \\ Department of Chemistry, Prairie View A\&M University, Prairie View, TX 77446, USA \\ Correspondence should be addressed to Ananda S.Amarasekara, asamarasekara@pvamu.edu
}

Received 29 December 2011; Accepted 7 February 2012

Academic Editor: Yuriy A. Knirel

Copyright (C) 2012 A. S. Amarasekara and B. Wiredu. This is an open access article distributed under the Creative Commons Attribution License, which permits unrestricted use, distribution, and reproduction in any medium, provided the original work is properly cited.

Brönsted acidic ionic liquid 1-(1-propylsulfonic)-3-methylimidazolium chloride (PSMIMCl) shows a higher catalytic activity than sulfuric acid in the hydrolysis of D-cellobiose to D-glucose in water at $90-120^{\circ} \mathrm{C}$. This catalytic activity enhancement is more significant at higher temperatures, and at $120^{\circ} \mathrm{C}$, PSMIMCl produced $64.5 \%$ glucose yield, whereas $\mathrm{H}_{2} \mathrm{SO}_{4}$ produced only $42.2 \%$ after $40 \mathrm{~min}$. reaction, and this is a $52.8 \%$ enhancement of catalytic activity due to the alkylimidazolium group attached to the sulfonic acid group. ${ }^{1} \mathrm{H}$ NMR monitoring of the D-cellobiose hydrolysis in PSMIMCl and sulfuric acid mediums failed to reveal intermediates in the hydrolysis reaction, and this is probably due to rapid conversion of the intermediate(s) to a mixture of Dglucose anomers with $\alpha: \beta \approx 1: 1.6$.

\section{Introduction}

Hydrolysis of lignocellulosic biomass to fermentable sugars is an essential step in the production of cellulosic-ethanol and is the most challenging step in the whole process [15]. Enzymatic hydrolysis is the widely used technology in current pilot plants, but this method requires a drastic pretreatment at high temperature and pressure to disrupt the strong hydrogen bonding network in cellulose, before exposure to the enzyme. Furthermore, commercialization of the enzymatic process is hindered by the prohibitive cost of the currently available enzyme preparations as well [6]. As an alternative to the enzymatic methods, dilute aqueous solution of sulfuric acid can also be used as a catalyst for the direct hydrolysis of cellulose at high temperature and pressure. Even though, the direct dilute acid saccharification gives lower sugar yields compared to enzymatic saccharification, a number of research groups have taken an interest in this old process [7-9] taking a second look at this technology due to its simplicity, and lower cost when compared to enzymatic saccharification, which anyhow requires an energy consuming pretreatment.

Ionic liquids are well known for their unique combination of attractive properties and as green solvents for numerous applications, but currently there is a marked interest in using ionic liquids in a number of other functions such as electrolytes [10], polymeric materials [11, 12], and catalysts [13]. In addition to this, 2002 discovery [14] of the use of ionic liquids as a cellulose dissolving solvent has sparked a new field of research on the use of ionic-liquidbased systems for the depolymerization of cellulose. The initial efforts in this direction were reported by $\mathrm{Li}$ et al. in 2007, where they published the use of catalytic amount of $\mathrm{H}_{2} \mathrm{SO}_{4}$ and controlled small amount of water for the hydrolysis of cellulose dissolved in butylmethylimidazolium chloride under mild conditions $[15,16]$. Later, the use of solid acid catalysts [17-19], as well as an immobilized acidic ionic liquid catalyst [20] was reported as well for the hydrolysis of cellulose dissolved in imidazolium ionic liquids. In 2009, our research group developed the use of 
Brönsted acidic ionic liquids with a built-in- $\mathrm{SO}_{3} \mathrm{H}$ group for the dual role of solvent and acid catalyst [21]. Where we reported that cellulose dissolved in Brönsted acidic ionic liquids 1-(alkyl sulfonic)-3-methylimidazolium chloride can be hydrolyzed by the addition of 2.0 equivalents of water per glucose unit of cellulose and heating the solution at $70^{\circ} \mathrm{C}$, and at atmospheric pressure to give glucose along with other reducing sugars in good yields [21].

As these ionic-liquid-based cellulose depolymerization methods require large volumes of ionic liquids as solvents, a complete recovery for reuse of the ionic liquid is essential in any large scale industrial process, and this is quite challenging since both the resulting sugars and these ionic liquids are highly soluble in water. Therefore, the use of an ionic liquid as a glycosidic bond hydrolysis catalyst in aqueous medium is a very attractive proposition [22]. However, the ionic liquid-cellulose system is typically studied under anhydrous conditions, and the use of ionic liquids in water as a catalyst is a relatively unexplored area. In a recent account of the use of ionic liquids in water, Dwiatmoko et al. reported [23] the enhancement of the catalytic activity of Nafion NR50 in the hydrolysis of cellulose model compound D-cellobiose to glucose, with the addition of halogenated ionic liquid 1-butyl3-methylimidazolium chloride, to the aqueous medium. Our interests [20-22] in the development of an efficient chemical cellulose depolymerization catalyst have led us to study the $\mathrm{SO}_{3} \mathrm{H}$ group substituted Brönsted acidic ionic liquid 1-(1propylsulfonic)-3-methylimidazolium chloride (PSMIMCl) (Figure 1) as a catalyst in aqueous medium for the hydrolysis of cellulose model compound D-cellobiose.

\section{Experimental}

2.1. Materials and Instrumentation. D-cellobiose (99.9\%), $\mathrm{D}_{2} \mathrm{O}(99.9 \%$ atom $\mathrm{D})$, sulfuric acid- $d_{2}(99.9 \%$ atom $\mathrm{D})$, 1-methylimidazole, and 1,3-propanesultone were purchased from Aldrich Chemical Co. Brönsted acidic ionic liquid 1 was prepared by condensation of 1-methylimidazole with 1,3-propanesultone and acidification of the resulting salt with conc. $\mathrm{HCl}$ according to the literature procedure [24, 25]. D-Cellobiose hydrolysis experiments were carried out in $25 \mathrm{~mL}$ glass vials with polycarbonate screw caps. These vials were heated in a preheated mineral oil bath placed on a VWR Scientific $1500 \mathrm{~W}$ ceramic hotplate with VT5 temperature controller of temperature accuracy $\pm 0.1^{\circ} \mathrm{C}$. Glucose concentrations in aqueous solutions were determined using a Carey $50 \mathrm{UV}$-Vis spectrophotometer and $1 \mathrm{~cm}$ quartz cells. ${ }^{1} \mathrm{H}$ NMR Spectra in $\mathrm{D}_{2} \mathrm{O}$ were recorded on a Varian Mercury plus spectrometer operating at $400 \mathrm{MHz}$, rd $=1 \mathrm{~s}$, spectral width of $6398 \mathrm{~Hz}$, and typically 16 scans were collected for spectra. All NMR spectra were collected at room temperature, $23^{\circ} \mathrm{C}$.

2.2. General Experimental Procedures for the Hydrolysis of D-Cellobiose Using Aqueous 1-(1-Propylsulfonic)-3-Methylimidazolium Chloride, and Sulfuric Acid Solutions at 90, 105 , and $120^{\circ} \mathrm{C}$. Stock solutions of the acids, 1-(1-propylsulfonic)-3-methylimidazolium chloride and sulfuric acid were

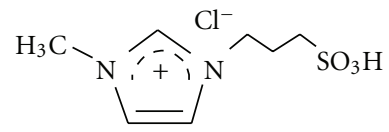

FIGURE 1: Brönsted acidic ionic liquid 1-(1-propylsulfonic)-3methylimidazolium chloride (PSMIMCl).

prepared by dissolving appropriate amounts of these acids in deionized water to give acid concentration of $0.0321 \mathrm{~mol}$ $\mathrm{H}^{+} / \mathrm{L}$ in each solution. The accuracy of the concentration was checked by titration with standardized aq. $\mathrm{NaOH}$ solution using phenolphthalein as the indicator.

D-Cellobiose $(0.0300 \mathrm{~g}, 0.0877 \mathrm{mmol})$ was dissolved in $10.00 \mathrm{~mL}$ of aqueous acid solution in a $25 \mathrm{~mL}$ glass vial with a skrew cap. The vial was firmly closed and heated in a preheated mineral oil bath maintained $\left( \pm 0.1^{\circ} \mathrm{C}\right)$ at the desired temperature for a specified length of time. Then, $0.30 \mathrm{~mL}$ Aliquots was withdrawn from the reaction solution at specific time intervals for glucose analysis, and an aliquot taken at room temperature before heating begins is referred to as zero time.

2.3. Glucose Assay. $0.30 \mathrm{~mL}$ of Aliquots taken from the reaction vial at specific time intervals was transferred to glass vials, neutralized by drop wise addition of $0.5 \mathrm{M}$ aq. $\mathrm{NaOH}$, and then diluted to $2.00 \mathrm{~mL}$. At zero time, reaction was started by adding $2.00 \mathrm{~mL}$ of glucose oxidase-peroxidase assay reagent $[26,27]$ to the vial and mixing thoroughly, and the vial was incubated in a water bath at $37^{\circ} \mathrm{C}$ for $30 \mathrm{~min}$. Then reaction was quenched by adding $2.00 \mathrm{~mL}$ of $6 \mathrm{M} \mathrm{HCl}$ to give a pink solution. The reagent blank was prepared by mixing $2.00 \mathrm{~mL}$ of deionized water and $2.00 \mathrm{~mL}$ of assay reagent and was treated similarly. Then the absorbance was immediately measured at $540 \mathrm{~nm}$ against the reagent blank, and glucose concentration in the solution was calculated by employing a standard curve prepared using glucose. The changes in percent yields of glucose produced during the hydrolysis of D-cellobiose in aqueous 1-(1propylsulfonic)-3-methylimidazolium chloride (PSMIMCl), and $\mathrm{H}_{2} \mathrm{SO}_{4}$ mediums at 90,105 , and $120^{\circ} \mathrm{C}$ are shown in Figure 2.

2.4. ${ }^{1} \mathrm{H}$ NMR Studies of D-Cellobiose Hydrolysis in $\mathrm{D}_{2} \mathrm{O}$ Using1-(1-Propylsulfonic)-3-Methylimidazolium Chloride and Sulfuric Acid-d $d_{2}$ as Catalysts. Two NMR samples were prepared in $5 \mathrm{~mm}$ NMR tubes by dissolving $10.0 \mathrm{mg}$ $(0.029 \mathrm{mmol})$ of $\mathrm{D}$-cellobiose in each tube and using $0.6 \mathrm{~mL}$ of $\mathrm{D}_{2} \mathrm{O}$ solutions of 1-(1-propylsulfonic)-3-methylimidazolium chloride and sulfuric acid- $d_{2}$ of acid strength $0.0321 \mathrm{~mol} \mathrm{H}^{+} / \mathrm{L}$. These samples were allowed to stabilize at room temperature for $24 \mathrm{hr}$, and then ${ }^{1} \mathrm{H}$ NMR spectra were recorded as the baseline data. Then the tubes were heated in a preheated mineral oil bath maintained at $90.0 \pm 0.1^{\circ} \mathrm{C}$, tubes were taken out of oil bath after specified time intervals, reaction was quenched by immersing the NMR tubes in cold water, and ${ }^{1} \mathrm{H}$ NMR spectra were recorded immediately. Then the tubes were returned to the thermostated 


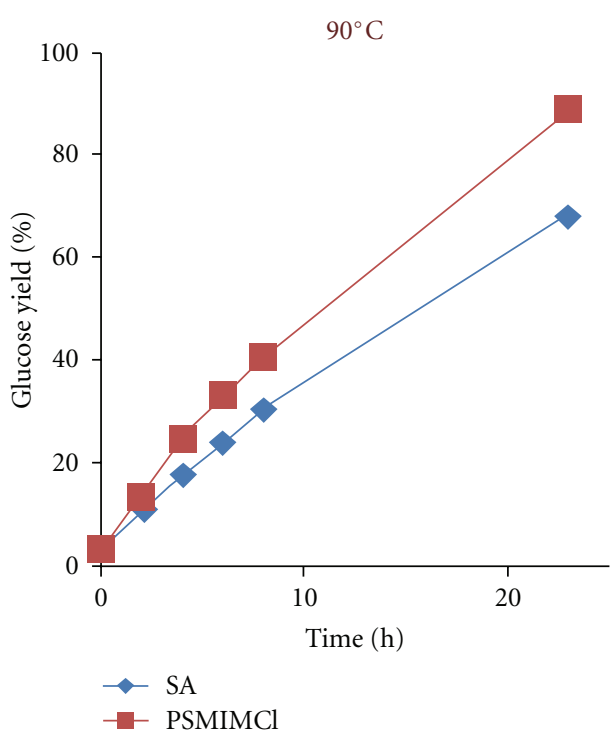

(a)

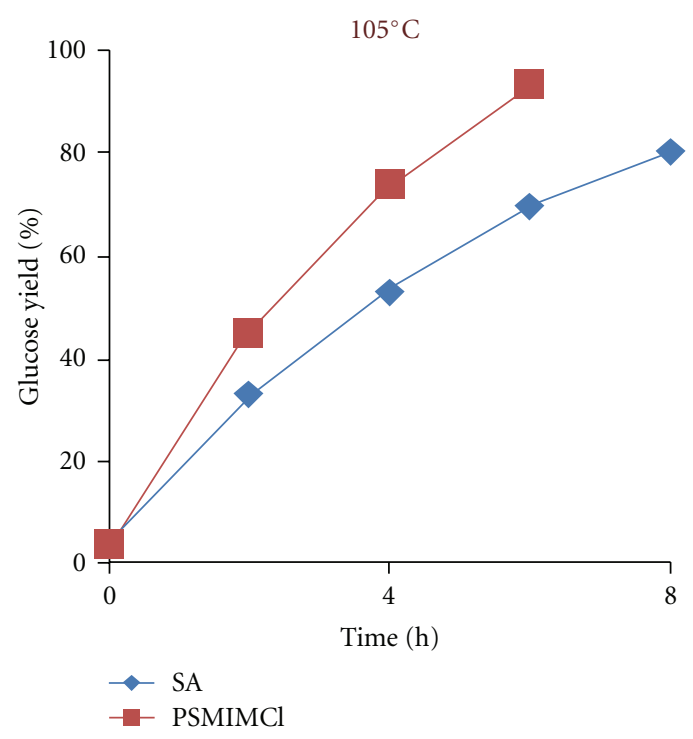

(b)

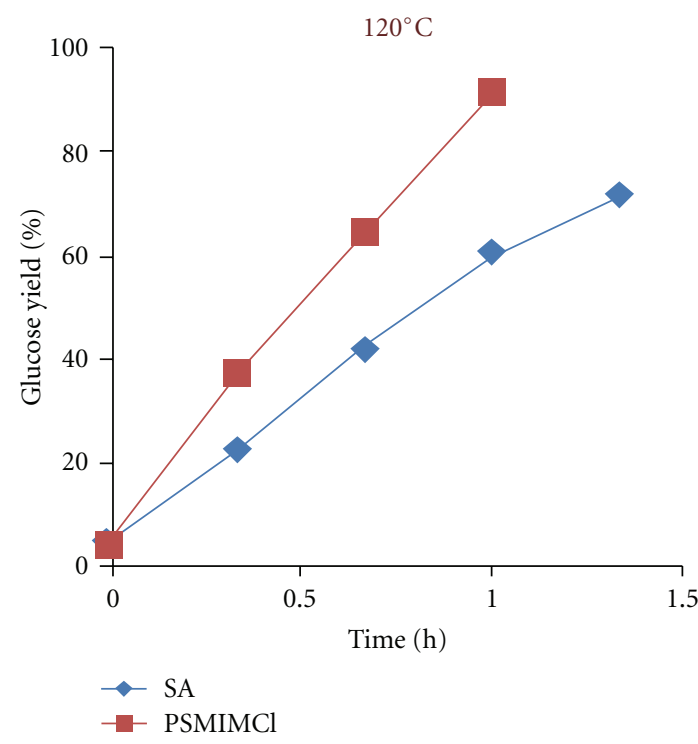

(c)

Figure 2: Change in percent yields of glucose produced during the hydrolysis of D-cellobiose in aqueous 1-(1-propylsulfonic)-3methylimidazolium chloride (PSMIMCl) and $\mathrm{H}_{2} \mathrm{SO}_{4}(\mathrm{SA})$ mediums at 90, 105, and $120^{\circ} \mathrm{C} .30 .0 \mathrm{mg}$ of D-cellobiose in $10.0 \mathrm{~mL}$ of $0.0321 \mathrm{~mol}$ $\mathrm{H}^{+} / \mathrm{L}$ acid mediums were used in all experiments.

oil bath for further heating, and NMR spectrums were recorded at regular time intervals to monitor the progress of the reaction. A typical series of spectra recorded for the sample using $0.0321 \mathrm{~mol} \mathrm{H}^{+} / \mathrm{L}$ of 1-(1-propylsulfonic)3-methylimidazolium chloride in $\mathrm{D}_{2} \mathrm{O}$ medium is shown in Figure 3. D-Cellobiose sample heated in sulfuric acid- $d_{2}$ medium also gave a similar series of spectra.

\section{Results and Discussion}

3.1. Hydrolysis of D-Cellobiose Using Aqueous 1-(1-Propylsulfonic)-3-Methylimidazolium Chloride and Sulfuric Acid
Solutions at 90, 105, and $120^{\circ} \mathrm{C}$. Catalytic activities of 1-(1propylsulfonic)-3-methylimidazolium chloride were compared with the activities of sulfuric acid of the same molar $\mathrm{H}^{+}$ion concentration, and according to Oscarson and Izatt's expression on temperature dependence of the first and second dissociation constants of sulfuric acid in water, it is assumed that $\mathrm{H}_{2} \mathrm{SO}_{4}$ completely dissociates to give two $\mathrm{H}^{+}$ ions in the temperature range of the study $[28,29]$. The changes in percent yields of glucose produced during the hydrolysis of D-cellobiose in aqueous PSMIMCl, and $\mathrm{H}_{2} \mathrm{SO}_{4}$ mediums at 90,105 and $120^{\circ} \mathrm{C}$ are shown in Figure 2. These experiments clearly show that Brönsted acidic ionic liquid PSMIMCl has a higher catalytic activity than sulfuric acid 


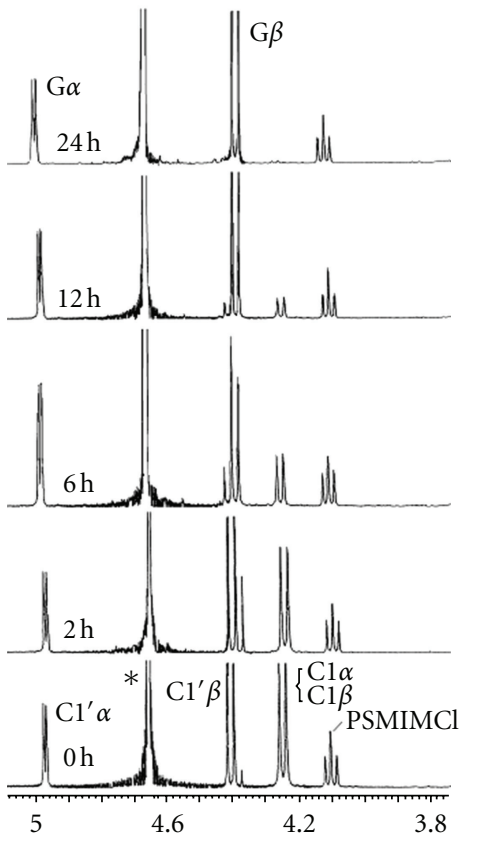

Figure 3: A series of ${ }^{1} \mathrm{H}$ NMR spectra recorded during the hydrolysis of D-cellobiose to D-glucose using $0.0321 \mathrm{~mol} \mathrm{H}^{+} / \mathrm{L}$ 1-(1-propylsulfonic)-3-methylimidazolium chloride (PSMIMCl) in $\mathrm{D}_{2} \mathrm{O}$ at $90^{\circ} \mathrm{C} .{ }^{*}=\mathrm{HDO}$.

of the same acid strength. Furthermore, catalytic activity enhancement is more significant at higher temperatures, for instance at $120^{\circ} \mathrm{C}$ PSMIMCl produced $64.5 \%$ glucose yield after 40 min. reaction, whereas $\mathrm{H}_{2} \mathrm{SO}_{4}$ produced only $42.2 \%$ during the same period, and this is a $52.8 \%$ enhancement of catalytic activity due to the alkylimidazolium group attached to the sulfonic acid group. This catalytic activity enhancement may be due to ion-dipole-type interactions of alkyl imidazolium groups and chloride ions with hydroxyl groups of D-cellobiose. In fact, Xiang has observed [30] similar interactions of 1-ethyl-3-methylimidazolium acetate with D-cellobiose in DMSO using ${ }^{13} \mathrm{C}$ NMR spectroscopy. Additionally, the glucose yield shows slight decrease with longer reaction times, especially at higher temperatures, and this could be due to well-known decomposition of glucose to various products like 5-hydroxymethylfurfural, 1,6 -anhydroglucose, levulinic acid, and formic acid in the acid medium $[31,32]$.

3.2. ${ }^{1} \mathrm{H}$ NMR Studies of D-Cellobiose Hydrolysis in $\mathrm{D}_{2} \mathrm{O}$ Using1-(1-Propylsulfonic)-3-Methylimidazolium Chloride and Sulfuric Acid- $d_{2}$ as Catalysts. A typical series of ${ }^{1} \mathrm{H}$ NMR spectra recorded during the hydrolysis of D-cello-biose in $0.0321 \mathrm{~mol} \mathrm{H}^{+} / \mathrm{L} \quad 1$-(1-propylsulfonic)-3-methylimidazolium chloride in $\mathrm{D}_{2} \mathrm{O}$ medium is shown in Figure 3. DCellobiose sample heated in sulfuric acid- $d_{2}$ medium also gave a similar series of spectra. The spectrum recorded at $t=0 \mathrm{~h}$. shows a mixture of $\alpha$ and $\beta$ anomers of $\mathrm{D}$ cellobiose and only a trace amount of D-glucose. The anomeric composition of D-cellobiose in this mixture was calculated as $\alpha:=\beta 1.00: 1.60$ using the peak area ratio
TABLe 1: $\alpha: \beta$ Anomeric ratios of D-glucose produced during the 1(1-propylsulfonic)-3-methylimidazolium chloride (PSMIMCl) and sulfuric acid catalyzed hydrolysis of D-cellobiose to D-glucose. $10.0 \mathrm{mg}$ of D-cellobiose in $0.60 \mathrm{~mL}$ acid solutions $(0.0321 \mathrm{~mol}$ $\mathrm{H}^{+} / \mathrm{L}$ ) were used.

\begin{tabular}{lcc}
\hline Time h. & \multicolumn{2}{c}{ Catalyst } \\
& $\begin{array}{cc}\text { PSMIMCl } \\
\alpha: \beta\end{array}$ & $\begin{array}{c}\mathrm{H}_{2} \mathrm{SO}_{4} \\
\alpha: \beta\end{array}$ \\
\hline 2 & $1: 1.56$ & $1: 1.62$ \\
6 & $1: 1.65$ & $1: 1.58$ \\
12 & $1: 1.60$ & $1: 1.59$ \\
24 & $1: 1.63$ & $1: 1.65$ \\
\hline
\end{tabular}

of two doublets at $4.97 \mathrm{ppm}(J=3.6 \mathrm{~Hz})$ and $4.40 \mathrm{ppm}$ $(J=8.4 \mathrm{~Hz}$, in Figure $3, t=0 \mathrm{~h}$ ), and this value is compatible with the reported anomeric ratio [33] of $\mathrm{D}$ cellobiose in water. A gradual increase in D-glucose and the disappearance of D-cellobiose is seen in the series of spectra recorded during the course of the reaction. Only the anomeric hydrogens of D-cellobiose and D-glucose could be assigned due to the complexity of the spectra shown in Figure 3. The anomeric ratios of D-glucose formed during the PSMIMCl and sulfuric acid catalyzed hydrolysis were calculated by using the following equations, assuming that anomeric ratio of D-cellobiose remains constant throughout the reaction.

$$
\begin{gathered}
C_{\alpha}+2 G_{\alpha}=\text { Peak area at } 4.97 \mathrm{ppm}, \\
C_{\beta}+2 G_{\beta}=\text { Peak area at } 4.37-4.42 \mathrm{ppm}, \\
C_{\alpha}+C_{\beta}=\text { Peak area at } 4.25 \mathrm{ppm},
\end{gathered}
$$

where, $C_{\alpha}=$ peak area of D-cellobiose $1 \alpha$ or $1^{\prime} \alpha$ hydrogen. $C_{\beta}$ = peak area of D-cellobiose $1 \beta$ or $1^{\prime} \beta$ hydrogen. $G_{\alpha}=$ peak area of D-glucose $1 \alpha$ hydrogen. $G_{\beta}=$ peak area of D-glucose $1 \beta$ hydrogen.

Calculated anomeric ratios of D-glucose produced remains approximately constant during the course of the reactions as seen in Table 1, and this may be due to a rapid equilibration of D-glucose formed. Furthermore, as seen in the array of NMR spectra of PSMIMCl-catalyzed hydrolysis of D-cellobiose in Figure 3, ${ }^{1} \mathrm{H}$ NMR study failed to reveal any reaction intermediates, and similarly NMR spectra of $\mathrm{H}_{2} \mathrm{SO}_{4}$-catalyzed reaction also showed no reaction intermediates. This can be explained by a mechanism involving a slow protonation of glycosidic oxygen in D-cellobiose and fast attack of water on the anomeric carbon, resulting fast hydrolysis D-cellobiose to D-glucose, as shown in the case of PSMIMCl catalyzed reaction in Figure 4.

\section{Conclusion}

We have shown that Brönsted acidic ionic liquid1-(1-propylsulfonic)-3-methylimidazolium chloride (PSMIMCl) has 


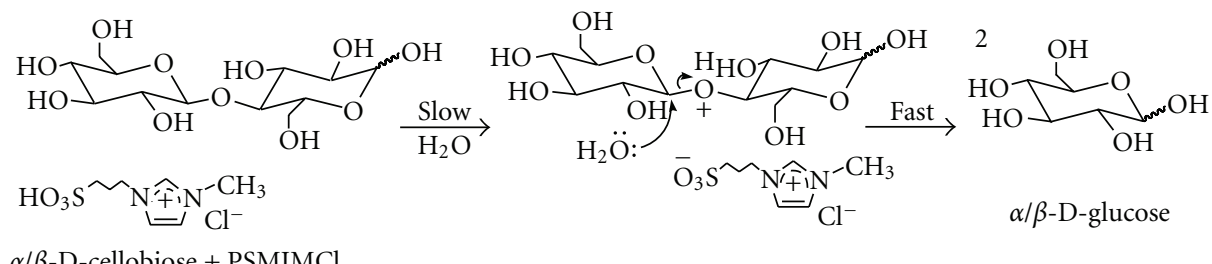

FIGURE 4: Proposed mechanism for Brönsted acidic ionic liquid 1-(1-propylsulfonic)-3-methylimidazolium chloride (PSMIMCl) catalyzed hydrolysis of D-cellobiose to D-glucose in water.

a higher catalytic activity than sulfuric acid in the hydrolysis of D-cellobiose to D-glucose in water at $90-120^{\circ} \mathrm{C}$. This catalytic activity enhancement is more significant at higher temperatures and may be due to an interaction of alkylimidazolium group with D-cellobiose. ${ }^{1} \mathrm{H}$ NMR monitoring of the PSMIMCl as well as sulfuric acid catalyzed D-cellobiose hydrolysis reactions at $90^{\circ} \mathrm{C}$ failed to show any intermediates in the reaction, and this is possibly due to fast conversion of any intermediate(s) to products.

\section{Acknowledgments}

Authors would like to thank Center for Environmentally Beneficial Catalysis (CEBC), University of Kansas, American Chemical Society: PRF Grant UR1-49436, NSF Grant CBET0929970, and USDA Grant CBG-2010-38821-21569 for financial support.

\section{References}

[1] J. Goettemoeller and A. Goettemoeller, Sustainable Ethanol: Biofuels, Biorefineries, Cellulosic Biomass, Flex-fuel Vehicles, and Sustainable Farming for Energy Independence, Prairie Oak, Maryville, Mo, USA, 2007.

[2] R. Katzen and D. J. Schell, Biorefineries_Industrial Processes and Products, vol. 1, Wiley-VCH, Weinheim, Germany, 2006, edited by B. Kamm, P.R. Gruber, M. Kamm.

[3] C. Wyman, Handbook on Bioethanol: Production and Utilization, Taylor \& Francis, Washington, DC, USA, 1996.

[4] G. W. Huber, S. Iborra, and A. Corma, "Synthesis of transportation fuels from biomass: chemistry, catalysts, and engineering," Chemical Reviews, vol. 106, no. 9, pp. 40444098, 2006.

[5] M. Balat and H. Balat, "Recent trends in global production and utilization of bio-ethanol fuel," Applied Energy, vol. 86, no. 11, pp. 2273-2282, 2009.

[6] R. K. Sukumaran, R. R. Singhania, G. M. Mathew, and A. Pandey, "Cellulase production using biomass feed stock and its application in lignocellulose saccharification for bio-ethanol production," Renewable Energy, vol. 34, no. 2, pp. 421-424, 2009.

[7] P. Lenihan, A. Orozco, E. O’Neill, M. N. M. Ahmad, D. W. Rooney, and G. M. Walker, "Dilute acid hydrolysis of lignocellulosic biomass," Chemical Engineering Journal, vol. 156, no. 2, pp. 395-403, 2010.

[8] G. Sanchez, L. Pilcher, C. Roslander, T. Modig, M. Galbe, and G. Liden, "Dilute-acid hydrolysis for fermentation of the Bolivian straw material Paja Brava," Bioresource Technology, vol. 93, no. 3, pp. 249-256, 2004.
[9] Q. Xiang, Y. Y. Lee, and R. W. Torget, "Kinetics of glucose decomposition during dilute-acid hydrolysis of lignocellulosic biomass," Applied Biochemistry and Biotechnology, vol. 113, pp. 1127-1138, 2004

[10] T. Sato, S. Marukane, T. Narutomi, and T. Akao, "High rate performance of a lithium polymer battery using a novel ionic liquid polymer composite," Journal of Power Sources, vol. 164, no. 1, pp. 390-396, 2007.

[11] A. S. Amarasekara and P. Shanbhag, "Synthesis and characterization of polymeric ionic liquid poly(imidazolium chloride1,3-diylbutane-1,4-diyl)," Polymer Bulletin, vol. 67, no. 4, pp. 623-629, 2011.

[12] A. S. Amarasekara, B. Callis, and B. Wiredu, "Synthesis and characterization of branched polymeric ionic liquids with imidazolium chloride segments," Polymer Bulletin, vol. 68, no. 4, pp. 901-908, 2011.

[13] H. Olivier-Bourbigou, L. Magna, and D. Morvan, "Ionic liquids and catalysis: recent progress from knowledge to applications," Applied Catalysis A, vol. 373, no. 1-2, pp. 1-56, 2010.

[14] R. P. Swatloski, S. K. Spear, J. D. Holbrey, and R. D. Rogers, "Dissolution of cellose with ionic liquids," Journal of the American Chemical Society, vol. 124, no. 18, pp. 4974-4975, 2002.

[15] C. Li and Z. K. Zhao, "Efficient acid-catalyzed hydrolysis of cellulose in ionic liquid," Advanced Synthesis and Catalysis, vol. 349, no. 11-12, pp. 1847-1850, 2007.

[16] C. Li, Q. Wang, and Z. K. Zhao, "Acid in ionic liquid: an efficient system for hydrolysis of lignocellulose," Green Chemistry, vol. 10, no. 2, pp. 177-182, 2008.

[17] R. Rinaldi, R. Palkovits, and F. Schüth, "Depolymerization of cellulose using solid catalysts in ionic liquids," Angewandte Chemie_International Edition, vol. 47, no. 42, pp. 8047-8050, 2008.

[18] Z. Zhang and Z. K. Zhao, "Solid acid and microwave-assisted hydrolysis of cellulose in ionic liquid," Carbohydrate Research, vol. 344, no. 15, pp. 2069-2072, 2009.

[19] S. J. Kim, A. A. Dwiatmoko, J. W. Choi, Y. W. Suh, D. J. Suh, and M. Oh, "Cellulose pretreatment with 1-n-butyl-3methylimidazolium chloride for solid acid-catalyzed hydrolysis," Bioresource Technology, vol. 101, no. 21, pp. 8273-8279, 2010.

[20] A. S. Amarasekara and O. S. Owereh, "Synthesis of a sulfonic acid functionalized acidic ionic liquid modified silica catalyst and applications in the hydrolysis of cellulose," Catalysis Communications, vol. 11, no. 13, pp. 1072-1075, 2010.

[21] A. S. Amarasekara and O. S. Owereh, "Hydrolysis and decomposition of cellulose in bronösted acidic ionic liquids under mild conditions," Industrial and Engineering Chemistry Research, vol. 48, no. 22, pp. 10152-10155, 2009.

[22] A. S. Amarasekara and B. Wiredu, "Degradation of cellulose in dilute aqueous solutions of acidic ionic liquid 
1-(1-propylsulfonic)-3-methylimidazolium chloride, and $p$ toluenesulfonic acid at moderate temperatures and pressures," Industrial and Engineering Chemistry Research, vol. 50, no. 21, pp. 12276-12280, 2011.

[23] A. A. Dwiatmoko, J. W. Choi, D. J. Suh, Y.-W. Suh, and H. H. Kung, "Understanding the role of halogen-containing ionic liquids in the hydrolysis of cellobiose catalyzed by acid resins," Applied Catalysis A, vol. 387, no. 1-2, pp. 209-214, 2010.

[24] Q. Yang, Z. Wei, H. Xing, and Q. Ren, "Brönsted acidic ionic liquids as novel catalysts for the hydrolyzation of soybean isoflavone glycosides," Catalysis Communications, vol. 9, no. 6, pp. 1307-1311, 2008.

[25] G. Y. Zhu, R. Wang, G. H. Liu, L. Q. Xu, B. Zhang, and X. Q. Wu, "Synthesis of multi-hydroxyl and sulfonyl dualfunctionalized room temperature ionic liquids," Chinese Chemical Letters, vol. 18, no. 6, pp. 633-635, 2007.

[26] H. U. Bergmeyer and E. Bernt, "Glucose determination with glucose oxidase and peroxidase," in Methods of Enzymatic Analysis, H. U. Bergmeyer, Ed., pp. 1205-1212, Academic Press, New York, NY, USA, 1974.

[27] D. A. T. Southgate, Determination of Food Carbohydrates, Applied Science Publishers, London, UK, 1961.

[28] L. Kupiainen, J. Ahola, and J. Tanskanen, "Comparison of formic and sulfuric acids as a glucose decomposition catalyst," Industrial and Engineering Chemistry Research, vol. 49, no. 18, pp. 8444-8449, 2010.

[29] J. L. Oscarson, R. M. Izatt, P. R. Brown, Z. Pawlak, S. E. Gillespie, and J. J. Christensen, "Thermodynamic quantities for the interaction of $\mathrm{SO}_{4}^{2-}$ with $\mathrm{H}^{+}$and $\mathrm{Na}^{+}$in aqueous solution from 150 to $320^{\circ} \mathrm{C}$," Journal of Solution Chemistry, vol. 17, no. 9, pp. 841-863, 1988.

[30] J. Zhang, H. Zhang, J. Wu, J. Zhang, J. He, and J. Xiang, "NMR spectroscopic studies of cellobiose solvation in EmimAc aimed to understand the dissolution mechanism of cellulose in ionic liquids," Physical Chemistry Chemical Physics, vol. 12, no. 8, pp. 1941-1947, 2010.

[31] Q. Xiang, Y. Y. Lee, and R. W. Torget, "Kinetics of glucose decomposition during dilute-acid hydrolysis of lignocellulosic biomass," Applied Biochemistry and Biotechnology A, vol. 115, no. 1-3, pp. 1127-1138, 2004.

[32] X. Huang, H. Duan, and S. A. Barringer, "Effects of buffer and temperature on formation of furan, acetic acid and formic acid from carbohydrate model systems," LWT-Food Science and Technology, vol. 44, no. 8, pp. 1761-1765, 2011.

[33] M. U. Roslund, P. Tähtinen, M. Niemitz, and R. Sjöholm, "Complete assignments of the ${ }^{1} \mathrm{H}$ and ${ }^{13} \mathrm{C}$ chemical shifts and $J_{\mathrm{H}, \mathrm{H}}$ coupling constants in NMR spectra of D-glucopyranose and all D-glucopyranosyl-D-glucopyranosides," Carbohydrate Research, vol. 343, no. 1, pp. 101-112, 2008. 


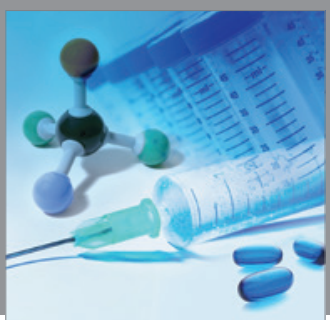

International Journal of

Medicinal Chemistry

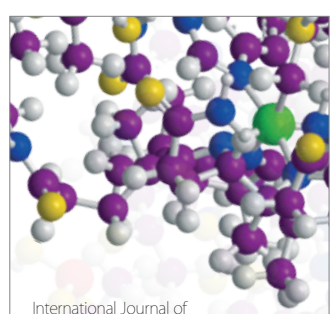

Carbohydrate Chemistry

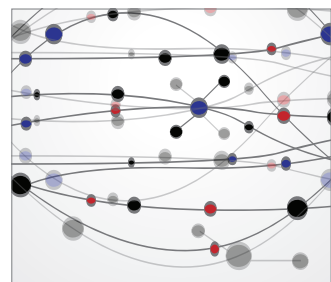

The Scientific World Journal
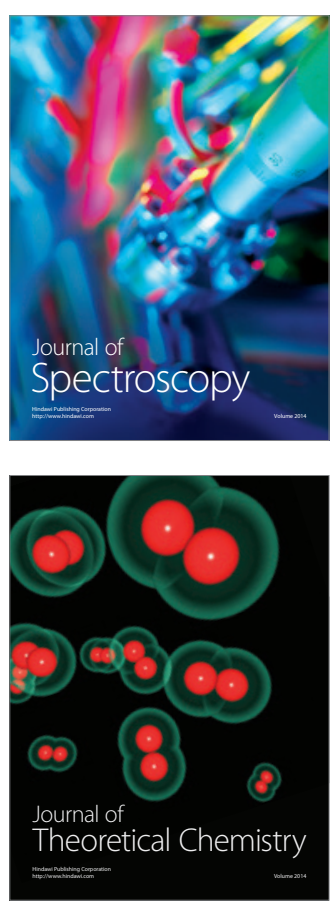
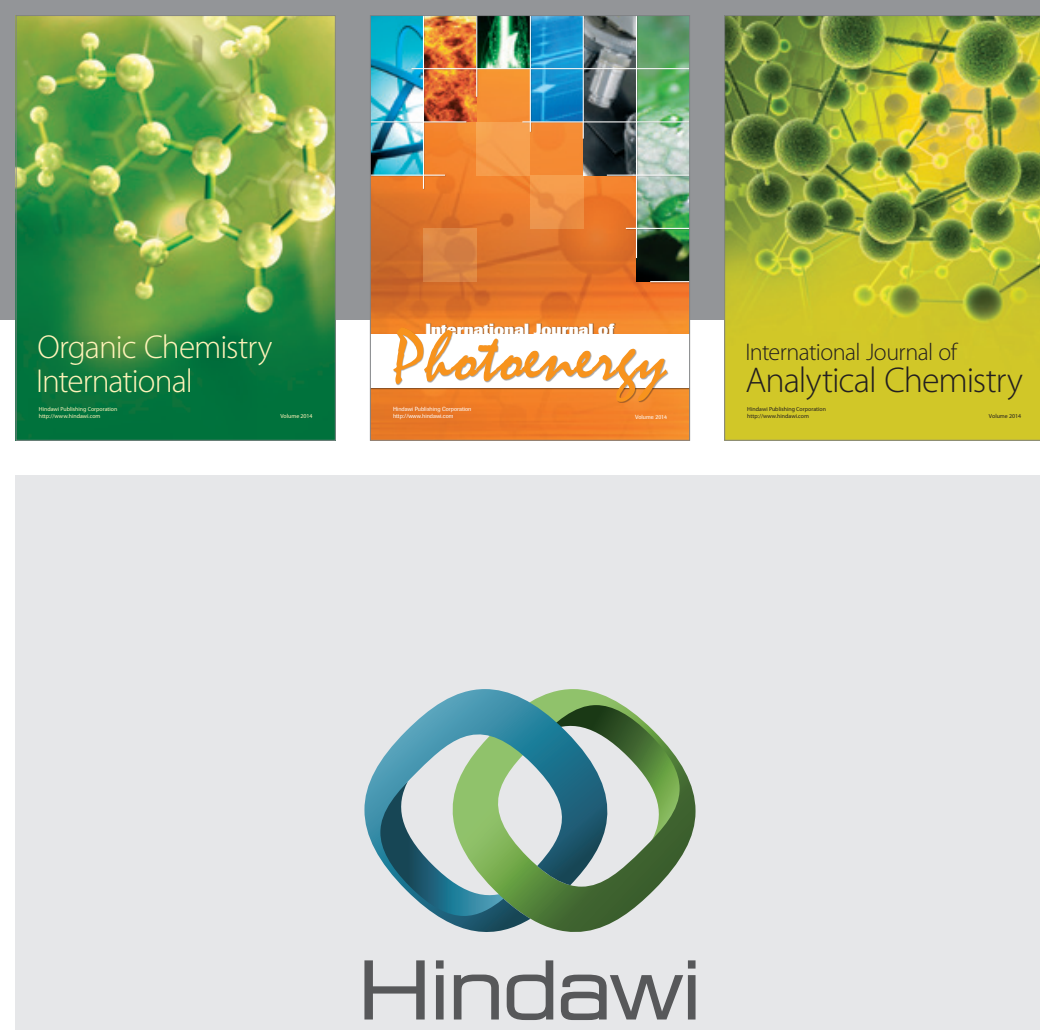

Submit your manuscripts at

http://www.hindawi.com
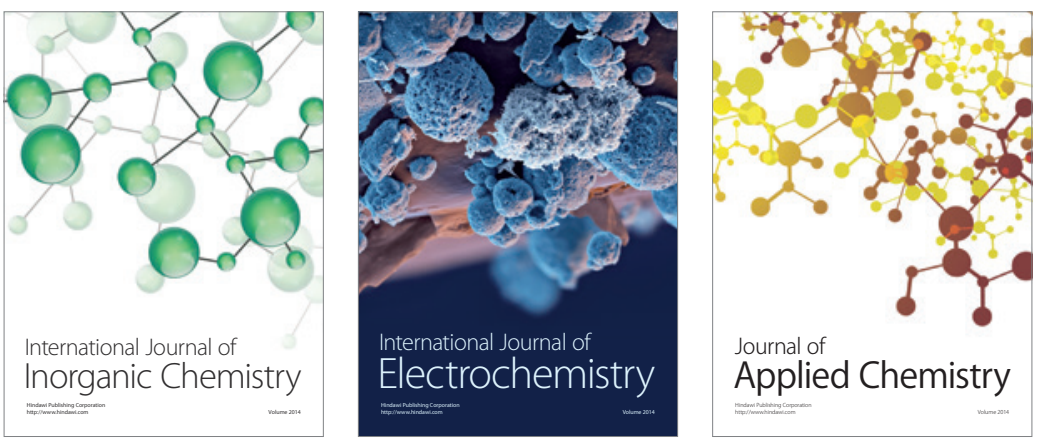

Journal of

Applied Chemistry
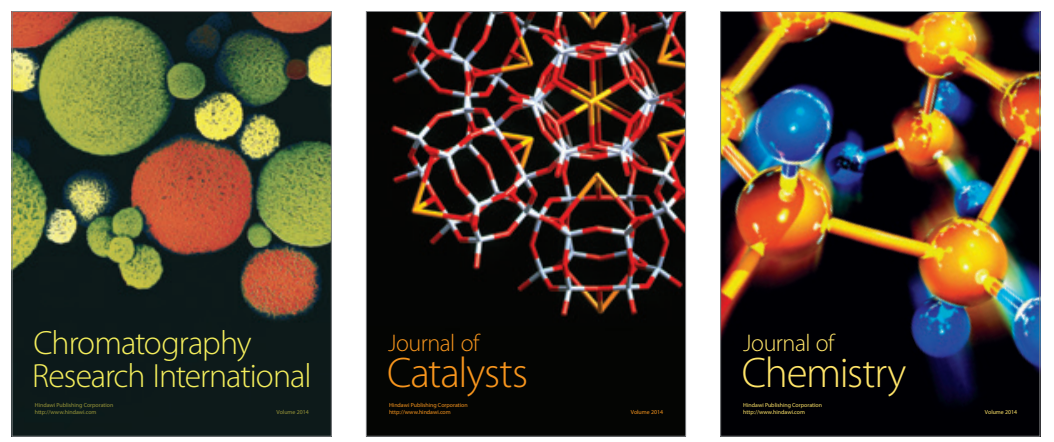
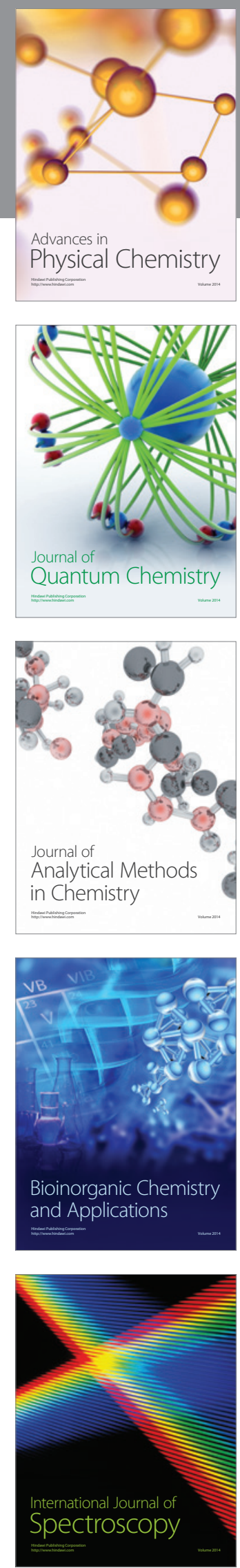